\title{
Increased Fasting Serum Level of Arsenic Caused by Intake of Fish Meat Promotes a Potential Risk of Hypertension
}

\section{Tingchao He}

Nagoya University Graduate School of Medicine Faculty of Medicine: Nagoya Daigaku Daigakuin Igakukei Kenkyuka Igakubu

\section{Nobutaka Ohgami}

Nagoya University Graduate School of Medicine Faculty of Medicine: Nagoya Daigaku Daigakuin Igakukei Kenkyuka Igakubu

\section{Shoko Ohnuma}

Nagoya University Graduate School of Medicine Faculty of Medicine: Nagoya Daigaku Daigakuin Igakukei Kenkyuka Igakubu

\section{Hisao Naito}

Nagoya University Graduate School of Medicine Faculty of Medicine: Nagoya Daigaku Daigakuin Igakukei Kenkyuka Igakubu

\section{Ichiro Yajima}

Nagoya University Graduate School of Medicine Faculty of Medicine: Nagoya Daigaku Daigakuin Igakukei Kenkyuka Igakubu

\section{Akira Tazaki}

Nagoya University Graduate School of Medicine Faculty of Medicine: Nagoya Daigaku Daigakuin Igakukei Kenkyuka Igakubu

\section{Takashi Tamura}

Nagoya University Graduate School of Medicine Faculty of Medicine: Nagoya Daigaku Daigakuin Igakukei Kenkyuka Igakubu

\section{Takaaki Kondo}

Nagoya University Graduate School of Medicine Faculty of Medicine: Nagoya Daigaku Daigakuin Igakukei Kenkyuka Igakubu

\section{Kenji Wakai}

Nagoya University Graduate School of Medicine Faculty of Medicine: Nagoya Daigaku Daigakuin Igakukei Kenkyuka Igakubu

\section{Masashi Kato ( $\sim$ katomasa@med.nagoya-u.ac.jp )}

Nagoya University Graduate School of Medicine Faculty of Medicine: Nagoya Daigaku Daigakuin Igakukei Kenkyuka Igakubu 


\section{Research Article}

Keywords: Arsenic, Japanese food, seafood, fish meat, prevalence of hypertension

Posted Date: August 3rd, 2021

DOl: https://doi.org/10.21203/rs.3.rs-748640/v1

License: (c) (i) This work is licensed under a Creative Commons Attribution 4.0 International License. Read Full License 
1 Increased fasting serum level of arsenic caused by intake of fish meat 2 promotes a potential risk of hypertension

3

4 Tingchao $\mathrm{He}^{1,4}$, Nobutaka Ohgami ${ }^{1,4}$, Shoko Ohnuma ${ }^{4}$, Hisao Naito ${ }^{1}$, Ichiro Yajima ${ }^{1,4}$, Akira

5 Tazaki $^{1,4}$, Takashi Tamura ${ }^{2}$, Takaaki Kondo ${ }^{3}$, Kenji Wakai ${ }^{2}$, Masashi Kato ${ }^{1,4, *}$

6

7 Departments of ${ }^{1}$ Occupational and Environmental Health, ${ }^{2}$ Preventive Medicine and

8 3Pathophysiological Laboratory Sciences, Nagoya University Graduate School of Medicine,

9 Nagoya, Japan. ${ }^{4}$ Voluntary Body for International Health Care in Universities, Aichi, Japan. 10

11 *Corresponding author: Masashi Kato, $\mathrm{MD}, \mathrm{PhD}$, Department of Occupational and

12 Environmental Health, Nagoya University Graduate School of Medicine, 65 Tsurumai-cho,

13 Showa-ku, Nagoya, Aichi 466-8550, Japan. Phone: +81-52-744-2122. Fax: +81-52-744-2124.

14 E-mail: katomasa@med.nagoya-u.ac.jp 


\section{Abstract}

Despite identification of arsenic intake from well drinking water in developing countries as a crucial hazard for health, the health effects of diet-mediated intake of arsenic on health in developed countries have remained unclear. The Japanese diet, which is regarded as a healthy diet, includes a high intake of seafoods that contain high levels of arsenic. The associations among intake of Japanese food including 54 food items classified into 6 categories, arsenic exposure and hypertension were investigated in 2,709 adults in Japan. Logistic regression analysis including serum sodium and potassium levels as confounders indicated a positive association between fasting serum level of arsenic (fsl-As) and prevalence of hypertension. Seaweed, bone-edible small fish and fish meat in seafoods were strong contributors to the increased fsl-As among the food items examined. Fish meat intake was identified as the greatest contributor to prevalence of hypertension. Since $94 \%$ of arsenic has been reported to be caused by dietary intake in Japan, our results suggest that increased fsl-As caused by intake of fish meat could be a potential risk for hypertension. Considering the worldwide trend of increased fish meat intake, arsenic in fish meat might be a new global hazardous material.

Keywords: Arsenic, Japanese food, seafood, fish meat, prevalence of hypertension

\section{Declarations:}

Funding This work was supported partly by Grants-in-Aids for Scientific Research (A) (19H01147) and (B) (17KT0033, 20H03929), challenging Exploratory Research (20K21708) and Scientific Research on Innovative Areas (16H06277) from the Ministry of Education, Culture, Sports, Science and Technology (MEXT), Kobayashi International Scholarship Foundation, Chukyo Longevity Medical and Promotion Foundation and Grant Program of Innovation for Future Society. The funders had no role in study design, data collection and analysis, decision to publish, or preparation of the manuscript.

Conflicts of interest The authors declare that there is no conflict of interest.

Availability of data and material The data that support the findings of this study are not available for a while since data analysis for publications are ongoing. 
Authors' contributions T.H. performed the data analysis. T.H., N.O. and M.K. wrote the manuscript. H.N., T.T., T.K. and K.W. collected samples and questionnaire from subjects. T.T., T.K., K.W. and M.K. developed the basic concept of this study. M.K. and N.O. conceived the associations between food intake and arsenic exposure. S.O., I.Y. and A.T. developed the methodology. S.O., H.N., I.Y. and A.T. analyzed human samples. M.K.

51 provided the research foundation, supervised the work and revised the final version of the 52 manuscript.

Ethics approval The manuscript in full has not been submitted or published anywhere. Ethics 54 committee of Nagoya University Graduate School of Medicine approved the study (approval numbers: 2008-0618 and 2013-0070).

56 Consent to participate Informed consent was obtained from all individual participants

57 included in the study.

Consent for publication All of the authors have read and approved the paper for submission 59 of publication. 


\section{Introduction}

Hypertension, a silent killer, is widely known as a typical symptom of lifestyle-related diseases that reduce the health span in humans. Dietary habits are known to be strong risk factors for hypertension (Ndanuko et al., 2016). Since sodium (Na) derived from food intake might be one of the strongest inducers of hypertension (Adrogué and Madias, 2014; Grillo et al., 2019), worldwide campaigns to decrease the intake of foods with large amounts of $\mathrm{Na}$ are ongoing. In contrast, potassium (K), a homologous element of sodium, derived from food intake might be a factor that decreases the incidence of hypertension (Adrogué and Madias, 2014; Stone et al., 2016). Those studies indicate that there is a strong contribution of elements such as sodium and potassium via food intake to the prevalence of hypertension.

Arsenic (As) is known as a representative toxic element (Kato et al., 2020; Li et al., 2018; Yajima et al., 2017). Various arsenic-mediated health risks including risks for oncogenic, neurogenic and cutaneous disorders have been reported (Li et al., 2017; Yajima et al., 2018; Zhong et al., 2019). On the other hand, the contribution of arsenic to the prevalence of hypertension has remained unclear because of inconsistent results regarding the association between urinary arsenic level and prevalence of hypertension in previous human studies (Jones et al., 2011; Moon et al., 2013). Moreover, there have been very few studies on the association between serum arsenic level and prevalence of hypertension in humans. Since the serum level of arsenic is greatly affected by last-minute intake of foods (Mandal and Suzuki, 2002), serum level of arsenic might be inappropriate for assessment of arsenic-mediated health risks. However, previous studies indicated that fasting serum levels of arsenic in addition to other elements such as iron, cadmium and mercury are stable (Nguyen et al., 2017; Özel et al., 2019), suggesting that their fasting levels are close to the constitutive serum levels. Fasting serum level of arsenic may therefore be a good marker for assessing the arsenic-mediated health risks including the risk for hypertension in humans.

Japanese food, which was designated as a UNESCO's intangible cultural heritage in 2013, with low calories and low fat has been believed to be healthy food. As represented by sushi, which is a combination of seafood and rice, consumption of seafood containing large amounts of arsenic is a characteristic of Japanese food (Uneyama et al., 2007). Since consumption of seafood has been increasing worldwide due to the increasing popularity of Japanese food, investigation of the health effects of Japanese food is needed to predict food-mediated health effects of Japanese food. However, there has been no study showing an association between a dietary source of arsenic exposure and prevalence of hypertension. 
In this study, we measured the fasting levels of serum arsenic in 2,709 adults in Japan. We then investigated the association between serum arsenic level and prevalence of hypertension. We finally identified a specific food that strongly affects the prevalence of hypertension among 54 food items classified into 6 food categories.

\section{Methods}

\subsection{Study population}

Subjects in this study were recruited from the second cross-sectional survey of the Japan Multi-Institutional Collaborative Cohort (J-MICC) Daiko Study (Hattori et al., 2016). A total of 2,808 participants aged 39-75 years were recruited from residents of Nagoya City in Japan. Subjects without serum samples $(n=99)$ were excluded from this study. After careful explanation of our protocol to all participants, informed consent was obtained in writing. The main study protocol was reviewed and approved by the Ethics Committees of Nagoya University Graduate School of Medicine (approval numbers: 2008-0618 and 2013-0070). This study was performed in accordance with relevant guidelines.

\subsection{Collection and measurements of biological samples}

The method for collecting biological samples was previously reported (Morita et al., 2011). All samples were stored at $-80{ }^{\circ} \mathrm{C}$ in the Graduate School of Medicine, Nagoya University. Total arsenic concentrations in all serum samples that had been passed through a $0.45-\mu \mathrm{m}$ filter were measured by an inductively coupled plasma mass spectrometer (ICP-MS; 7500cx, Agilent Technologies) following the method previously described (He et al., 2019; Li et al., 2017; Ohgami et al., 2016).

\subsection{Questionnaire survey}

The subjects were requested to complete a self-administered questionnaire that included questions on general characteristics, disease history, family history of hypertension, physical activity, and smoking and drinking habits. The participants answered the questions at home to ensure completeness, and accuracy and consistency, trained staff checked the questionnaires with participants face-to-face on the enrollment day.

A validated food-frequency questionnaire (FFQ) consisting of questions on a total of 54 items of food and beverages was used for surveying subjects' dietary habits in the past year. The frequencies of intake of rice, bread and noodles were divided into 6 categories: (1) rarely, (2) 1-3 times monthly, (3) 1 or 2 times weekly, (4) 3 or 4 times weekly, (5) 5 or 6 times weekly 
129 and (6) $\geq 1$ time daily. The frequencies of intake of other foods were divided into 8 categories:

130 (1) rarely, (2) 1 or 3 times monthly, (3) 1 or 2 times weekly, (4) 3 or 4 times weekly, (5) 5 or 6 131 times weekly, (6) once daily, (7) twice daily and (8) 3 times daily. Foods were classified into 6 132 categories: cereals/beans, livestock/dairy products, seafood, vegetables/fruits, confectionery 133 and beverages. Each category was calculated by summing up all food intake daily in the same 134 classification and was divided into low, medium and high intake groups by tri-sectional 135 quantiles.

Intake of specific seafood items was also divided into low, medium and high intake groups. For fish meat, seaweed and bone-edible small fish, $\leq 2$ times weekly, 3-6 times weekly, and $\geq 1$ time daily were defined as low intake, medium intake and high intake, respectively. For intake of canned tuna, squid/octopus/shrimp/crab, shellfish and fish roe, $\leq 3$ times monthly, 1 or 2 times weekly, and $\geq 5$ times weekly were defined as low intake, medium intake and high intake, respectively. For fish-paste products, $\leq 2$ times weekly, 3 or 4 times weekly, and $\geq 5$ times weekly were defined as low intake, medium intake and high intake, respectively.

\subsection{Health examination and assessment of other covariates}

Blood pressure was measured twice in a seated position with a standard automated blood pressure measurement monitor (HEM-1000, Omron, Japan). All of the subjects rested for 5 minutes before the first measurement and for 2 minutes before the second measurement (Morita et al., 2011). According to previous studies (Ghosh et al., 2016; Wu et al., 2018), hypertension was defined by one of the following conditions: (1) previous diagnosis of hypertension, (2) systolic blood pressure $\geq 140 \mathrm{mmHg}$, (3) diastolic blood pressure $\geq 90 \mathrm{mmHg}$, and (4) currently taking anti-hypertension medicine. Body measurements (height and body weight) were performed by trained staff in health checkups, and body mass index (BMI) was calculated after adjustment for wearing clothes. Information on physical activities during leisure time was

154 obtained in 3 categories: light activity (walking, golf, etc.), moderate activity (jogging, 155 swimming, etc.) and heavy activity (football, marathons, etc.). All activities were reported in 156 frequency and average time per week. Metabolic equivalents (METs) for light, moderate and heavy activities are 3.3, 4.0 and 8.0, respectively, as previously reported (Nishida et al., 2020). METs-hours-per week were calculated to assess physical activity by summing up the multiplications of time spent in each activity.

\subsection{Statistical analysis}


All analyses were conducted by SPSS (Statistical Package for the Social Sciences) software version 25.0 (SPSS Inc., Chicago, IL, USA). All statistical tests were 2-sided, and p $<0.05$ was considered to be significant. Values are presented as means \pm standard deviations (SDs) and as medians (interquartile ranges) for normal and abnormal distributions, respectively, and as numbers (percentages) for categorical variables. Binary logistic regression was used to investigate the associations between food intake and serum arsenic levels and we considered several variables for inclusion in the final covariates-adjusted model: gender, age, BMI, and smoking and drinking (current or not current) habits as shown previously (Al Hossain et al., 2019). For categorical variables, the lowest group was considered as a reference.

\section{Results}

3.1. Characteristics of subjects.

The subjects of this study were 2709 adults (26.7\% males and $73.3 \%$ females) in Japan, and the basic characteristics of the subjects are shown in Table 1. The mean age of the subjects was 58.9 years [standard deviation (SD): 9.8 years], and the median of arsenic concentrations in fasting serum was 0.7 [interquartile range (IQR): 2.3] $\mu \mathrm{g} / \mathrm{L}$. Of the 2709 subjects, 697 (25.7\%) were diagnosed as having hypertension. Analysis of the median food intake frequencies showed that the highest and lowest intake levels were for beverages and confectionery, respectively. The median intake frequency of seafood was more than once per day.

\subsection{Association between serum arsenic level and hypertension.}

The association between fasting serum levels of arsenic and prevalence of hypertension is shown in Fig. 1. The cut-off value in serum was determined by the receiver operating characteristic (ROC) curve to be $1.7 \mu \mathrm{g} / \mathrm{L}$. In the original model, a significant positive association was found between arsenic in fasting serum and hypertension [odd ratios (ORs) with 95\% confidence interval (CI): $1.612(1.348,1.928), \mathrm{p}<0.001]$. The significant association remained after adjustment for lifestyle-related factors and family history of hypertension $[\mathrm{OR}=1.385(1.137,1.688), \mathrm{p}=0.001]$ and after adjustment for sodium and potassium levels in

\subsection{Associations between food intake and serum arsenic level.}

The relationships between 6 food categories and fasting serum level of arsenic were investigated by using a covariate-adjusted model (Fig. 2). There was a significant positive association between high intake of seafood and high level of serum arsenic [OR $=1.909$ (1.490, 
$2.447), \mathrm{p}<0.001]$. In contrast, high intake of livestock/dairy products was negatively associated with serum level of arsenic [OR $=0.644(0.512,0.811), \mathrm{p}<0.001]$. The relative contribution of each food category to arsenic level is shown in Table 2. The contribution of seafood intake to serum level of arsenic was highest (25.3\%) among the food categories, followed by livestock/dairy products $(9.6 \%)$ and vegetables/fruits $(4.9 \%)$, and the contribution of confectionery intake was the smallest $(0.3 \%)$. The relative contribution of intake of cereals/beans was not high but was same as the contribution of beverage intake (1.8\%) to serum level of arsenic.

3.4. Associations among seafood intake, serum arsenic level and hypertension.

Based on the contribution of seafood to increased serum level of arsenic, the associations between seafood items and fasting serum level of arsenic were investigated by using a covariate-adjusted model (Fig. 3). Analysis of 8 kinds of seafoods indicated that intake of fish meat [medium: OR $=1.387(1.156,1.663), \mathrm{p}<0.001$; high: $\mathrm{OR}=1.855(1.197,2.877), \mathrm{p}=$ 0.006], intake of bone-edible small fish [high: $\mathrm{OR}=1.656(1.084,2.530), \mathrm{p}=0.020$ ], intake of seaweed $[\mathrm{OR}=1.413(1.050,1.901), \mathrm{p}=0.022]$ and intake of squid/octopus/shrimp/crab [medium: $\mathrm{OR}=1.303(1.058,1.605), \mathrm{p}=0.013$ ] were associated with a high level of serum arsenic. In contrast, intake of canned tuna [high: $\mathrm{OR}=0.408(0.219,0.761), \mathrm{p}=0.005]$ was negatively associated with serum level of arsenic.

Based on the contribution of 3 specific seafood items (seaweed, bone-edible small fish and fish meat) to serum level of arsenic, the associations between seafood items and prevalence of hypertension were further investigated by using the covariate-adjusted model (Fig. 4). There was a significant association of prevalence of hypertension with intake of fish meat [high: OR

$219=1.703(1.045,2.775), \mathrm{p}=0.033]$ but not with intake of seaweed or intake of bone-edible small 220 fish.

\section{Discussion}

This study demonstrated a novel association between fasting serum level of arsenic and prevalence of hypertension in 2,709 adults in Japan. Our results partially correspond to the results of a previous study showing a positive association between fasting serum level of arsenic and levels of systolic and diastolic blood pressure but not prevalence of hypertension (Gao et al., 2018). These results suggest that an increased fasting serum level of arsenic is a risk factor for hypertension as was previously reported for sodium and potassium (Ekmekcioglu et al., 2016; Radhika et al., 2007; Strazzullo et al., 2001). In previous animal studies, exposure to 
arsenic has been shown to suppress aortic vasodilation caused by inhibition of endothelial nitric oxide synthase (Lee et al., 2003) and to induce hypertension in rats (Sarath et al., 2014).

In this study, we tried to find the source of serum arsenic. Well drinking water contaminated with arsenic has been shown to be a major source of arsenic in humans in developing countries including Bangladesh (Kato et al., 2013), Vietnam (Ilmiawati et al., 2016) and Afghanistan (Kato et al., 2016). However, drinking water provided as tap water in Japan has been estimated to be a minor (less than 2\%) source of exposure to arsenic (Ohno et al., 2010). Since 94\% of arsenic was shown to be derived from the diet in Japan (Ohno et al., 2010), the contribution of each Japanese food to fasting serum level of arsenic was further investigated. Seafood was identified as the main contributor to the serum level of arsenic among the foods that were classified into 6 categories according to a previous study (Nanri et al., 2016). Correspondingly, it was estimated by the pseudo R Square test that there was more than $25 \%$ contribution of seafood to the serum arsenic level among all of the confounders including food intake. Further analysis focusing on 8 items of seafood showed that seaweed, bone-edible small fish and fish meat are associated with an increase in fasting serum arsenic level. These results suggest that intake of seafood, especially seaweed, bone-edible small fish and fish meat, could be a major source of increase in the fasting serum level of arsenic. The results of our study conducted in Japan correspond to the results of previous studies showing that seafood is a major source of exposure to arsenic in Mediterranean areas and other European countries (Filippini et al., 2018; Miklavčič et al., 2013).

Intake of arsenic from well drinking water has been shown to be an important health risk for people in developing countries (Kato et al., 2020; Kumasaka et al., 2013; Li et al., 2017; Yajima et al., 2018; Yajima et al., 2015). The aim of our study was to elucidate the health risk of arsenic from dietary intake in Japan. A significant association between intake of fish meat and prevalence of hypertension was found in our study. Our results suggest that intake of fish meat is a potential risk for hypertension through increasing the fasting serum level of arsenic. In contrast, intake of seafoods to prevent hypertension was recommended in a previous study (Filippini et al., 2018). Fish consumption per capita in Japan (around $60 \mathrm{~kg} /$ year) is the highest in the world (Guillen et al., 2019). Almost half of the participants in our study had a high frequency of fish meat intake (more than 3 times per week). Considering that the level of arsenic in fish meat is higher than the levels in other tissues including the intestine, gills and mouthpieces (Shah et al., 2009), the dietary habit of a high frequency of fish meat intake in Japan may result in the arsenic-mediated hypertension in this study. On the other hand, a salty diet including intake of soy sauce that is used when eating raw fish meat (sashimi) may have a 
264 limited effect on the prevalence of hypertension because the positive association between fish meat intake and prevalence of hypertension was maintained after adding information about serum levels of sodium and potassium as confounding factors.

According to the Food and Agriculture Organization (FAO) of the United Nations, the rate of global fish consumption has been increasing and outpacing the rate of world population growth and the rate of consumption of meat from all other animals for the past six decades (FAO, 2020). Thus, arsenic exposure via intake of fish meat is not limited to Japan. Further investigation with a global perspective is needed to assess the health effects of arsenic via intake of fish meat.

273

\section{Conclusion}

Individual associations between arsenic levels and intake of food items such as fish meat, shellfish and seaweed have been reported (Filippini et al., 2018). An association between fasting serum level of arsenic and blood pressure has also been reported (Gao et al., 2018).

278 Since exposure to arsenic mainly originates from the diet in Japan (Ohno et al., 2010), individual associations should be comprehensively considered for evaluation of the effect of arsenic exposure via food intake on the prevalence of hypertension. However, there is no direct evidence for associations among food intake, arsenic exposure and prevalence of hypertension.

282 This study demonstrated for the first time that an increased fasting serum level of arsenic caused

283 by intake of fish meat is a potential risk for hypertension. Due to the rapid increase in worldwide 284 consumption of seafood, the effects of arsenic exposure caused by intake of seafood on human health should be addressed. 


\section{References}

Adrogué, H.J., and Madias, N.E. (2014). The impact of sodium and potassium on hypertension risk. Semin Nephrol 34, 257-272. https://doi.org/10.1016/j.semnephrol.2014.04.003

Al Hossain, M.M.A., Yajima, I., Tazaki, A., Xu, H., Saheduzzaman, M., Ohgami, N., Ahsan, N., Akhand, A.A., and Kato, M. (2019). Chromium-mediated hyperpigmentation of skin in male tannery workers in Bangladesh. Chemosphere 229, 611-617. https://doi.org/10.1016/j.chemosphere.2019.04.112 Ekmekcioglu, C., Elmadfa, I., Meyer, A.L., and Moeslinger, T. (2016). The role of dietary potassium in hypertension and diabetes. Journal of physiology and biochemistry 72, 93-106. https://doi.org/10.1007/s13105-015-0449-1

FAO (2020). The State of World Fisheries and Aquaculture, Sustainability in action. Rome. https://doi.org/10.4060/ca9229en.

300 Filippini, T., Malavolti, M., Cilloni, S., Wise, L.A., Violi, F., Malagoli, C., Vescovi, L., and 301 Vinceti, M. (2018). Intake of arsenic and mercury from fish and seafood in a Northern Italy community. Food and Chemical Toxicology 116, 20-26.

303 https://doi.org/10.1016/j.fct.2018.04.010

304 Gao, Y., Zhao, Z., Yang, L., Liu, X., Xing, X., Zhang, H., Yun, J., Ou, X., Su, X., Lu, Y., et 305 al. (2018). Arsenic exposure assists ccm3 genetic polymorphism in elevating blood pressure.

306 Oncotarget 9, 4915-4923. https://doi.org/10.18632/oncotarget.23518

307 Ghosh, S., Mukhopadhyay, S., and Barik, A. (2016). Sex differences in the risk profile of 308 hypertension: a cross-sectional study. BMJ open 6, e010085.

309 http://dx.doi.org/10.1136/bmjopen-2015-010085

310 Grillo, A., Salvi, L., Coruzzi, P., Salvi, P., and Parati, G. (2019). Sodium Intake and

311 Hypertension. Nutrients 11. https://doi.org/10.3390/nu11091970

312 Guillen, J., Natale, F., Carvalho, N., Casey, J., Hofherr, J., Druon, J.-N., Fiore, G., Gibin, M., 313 Zanzi, A., and Martinsohn, J.T. (2019). Global seafood consumption footprint. Ambio 48,

314 111-122. https://doi.org/10.1007/s13280-018-1060-9

315 Hattori, Y., Naito, M., Satoh, M., Nakatochi, M., Naito, H., Kato, M., Takagi, S., Matsunaga, 316 T., Seiki, T., Sasakabe, T., et al. (2016). Metallothionein MT2A A-5G Polymorphism as a 317 Risk Factor for Chronic Kidney Disease and Diabetes: Cross-Sectional and Cohort Studies.

318 Toxicol Sci 152, 181-193. https://doi.org/10.1093/toxsci/kfw080 
319 He, T., Ohgami, N., Li, X., Yajima, I., Negishi-Oshino, R., Kato, Y., Ohgami, K., Xu, H., 320 Ahsan, N., and Akhand, A.A. (2019). Hearing loss in humans drinking tube well water with 321 high levels of iron in arsenic-polluted area. Scientific reports 9, 1-9.

322 https://doi.org/10.1038/s41598-019-45524-1

323 Ilmiawati, C., Thang, N.D., Iida, M., Maeda, M., Ohnuma, S., Yajima, I., Ohgami, N.,

324 Oshino, R., Al Hossain, M.M., Ninomiya, H., et al. (2016). Limited effectiveness of

325 household sand filters for removal of arsenic from well water in North Vietnam. Journal of

326 water and health 14, 1032-1040. https://doi.org/10.2166/wh.2016.254

327 Jones, M.R., Tellez-Plaza, M., Sharrett, A.R., Guallar, E., and Navas-Acien, A. (2011). Urine

328 arsenic and hypertension in US adults: the 2003-2008 National Health and Nutrition

329 Examination Survey. Epidemiology 22, 153-161. doi: 10.1097/EDE.0b013e318207fdf2.

330 Kato, M., Azimi, M.D., Fayaz, S.H., Shah, M.D., Hoque, M.Z., Hamajima, N., Ohnuma, S.,

331 Ohtsuka, T., Maeda, M., and Yoshinaga, M. (2016). Uranium in well drinking water of

332 Kabul, Afghanistan and its effective, low-cost depuration using Mg-Fe based hydrotalcite-like

333 compounds. Chemosphere 165, 27-32. https://doi.org/10.1016/j.chemosphere.2016.08.124

334 Kato, M., Kumasaka, M.Y., Ohnuma, S., Furuta, A., Kato, Y., Shekhar, H.U., Kojima, M.,

335 Koike, Y., Dinh Thang, N., Ohgami, N., et al. (2013). Comparison of Barium and Arsenic

336 Concentrations in Well Drinking Water and in Human Body Samples and a Novel

337 Remediation System for These Elements in Well Drinking Water. PloS one 8, e66681.

338 https://doi.org/10.1371/journal.pone.0066681

339 Kato, M., Ohgami, N., Ohnuma, S., Hashimoto, K., Tazaki, A., Xu, H., Kondo-Ida, L., Yuan,

340 T., Tsuchiyama, T., and He, T. (2020). Multidisciplinary approach to assess the toxicities of

341 arsenic and barium in drinking water. Environmental health and preventive medicine 25, 1-7.

342 https://doi.org/10.1186/s12199-020-00855-8

343 Kumasaka, M.Y., Yamanoshita, O., Shimizu, S., Ohnuma, S., Furuta, A., Yajima, I., Nizam,

344 S., Khalequzzaman, M., Shekhar, H.U., and Nakajima, T. (2013). Enhanced carcinogenicity

345 by coexposure to arsenic and iron and a novel remediation system for the elements in well

346 drinking water. Archives of toxicology 87, 439-447. https://doi.org/10.1007/s00204-012-

$347 \quad \underline{0964-6}$

348 Lee, M.Y., Jung, B.I., Chung, S.M., Bae, O.N., Lee, J.Y., Park, J.D., Yang, J.S., Lee, H., and

349 Chung, J.H. (2003). Arsenic-induced dysfunction in relaxation of blood vessels.

350 Environmental health perspectives 111, 513-517. https://doi.org/10.1289/ehp.5916

351 Li, X., Ohgami, N., Omata, Y., Yajima, I., Iida, M., Oshino, R., Ohnuma, S., Ahsan, N.,

352 Akhand, A.A., and Kato, M. (2017). Oral exposure to arsenic causes hearing loss in young 
people aged 12-29 years and in young mice. Scientific reports 7, 6844 . N., and Akhand, A.A. (2018). Arsenic level in toenails is associated with hearing loss in humans. PloS one 13, e0198743. https://doi.org/10.1371/journal.pone.0198743 Mandal, B.K., and Suzuki, K.T. (2002). Arsenic round the world: a review. Talanta 58, 201235. https://doi.org/10.1016/S0039-9140(02)00268-0 Miklavčič, A., Casetta, A., Snoj Tratnik, J., Mazej, D., Krsnik, M., Mariuz, M., Sofianou, K., Spirić, Z., Barbone, F., and Horvat, M. (2013). Mercury, arsenic and selenium exposure levels in relation to fish consumption in the Mediterranean area. Environmental research 120, 7-17. https://doi.org/10.1016/j.envres.2012.08.010

Moon, K.A., Guallar, E., Umans, J.G., Devereux, R.B., Best, L.G., Francesconi, K.A., Goessler, W., Pollak, J., Silbergeld, E.K., Howard, B.V., et al. (2013). Association between exposure to low to moderate arsenic levels and incident cardiovascular disease. A prospective cohort study. Annals of internal medicine 159, 649-659. https://doi.org/10.7326/0003-4819$\underline{159-10-201311190-00719}$

Morita, E., Hamajima, N., Hishida, A., Aoyama, K., Okada, R., Kawai, S., Tomita, K., Kuriki, S., Tamura, T., and Naito, M. (2011). Study profile on baseline survey of Daiko study in the Japan multi-institutional collaborative cohort study (J-MICC study). Nagoya journal of medical science 73, 187. https://pubmed.ncbi.nlm.nih.gov/21928700/ Nanri, H., Nishida, Y., Nakamura, K., Tanaka, K., Naito, M., Yin, G., Hamajima, N., Takashima, N., Suzuki, S., Nindita, Y., et al. (2016). Associations between Dietary Patterns, ADRß2 Gln27Glu and ADRß3 Trp64Arg with Regard to Serum Triglyceride Levels: J-MICC Study. Nutrients 8. https://doi.org/10.3390/nu8090545 Ndanuko, R.N., Tapsell, L.C., Charlton, K.E., Neale, E.P., and Batterham, M.J. (2016). Dietary Patterns and Blood Pressure in Adults: A Systematic Review and Meta-Analysis of Randomized Controlled Trials. Adv Nutr 7, 76-89. https://doi.org/10.3945/an.115.009753 Nguyen, L.T., Buse, J.D., Baskin, L., Sadrzadeh, S.M.H., and Naugler, C. (2017). Influence of diurnal variation and fasting on serum iron concentrations in a community-based population. Clin Biochem 50, 1237-1242. https://doi.org/10.1016/j.clinbiochem.2017.09.018 Nishida, Y., Hachiya, T., Hara, M., Shimanoe, C., Tanaka, K., Sutoh, Y., Shimizu, A., Hishida, A., Tsukamoto, M., and Kadomatsu, Y. (2020). The interaction between ABCA1 polymorphism and physical activity on the HDL-cholesterol levels in a Japanese population. Journal of lipid research 61, 86-94. https://doi.org/10.1194/jlr.P091546 

Wakai, K., Ohnuma, S., et al. (2016). Epidemiological analysis of the association between hearing and barium in humans. Journal of exposure science \& environmental epidemiology 26, 488-493. https://doi.org/10.1038/jes.2015.62

391 Ohno, K., Ishikawa, K., Kurosawa, Y., Matsui, Y., Matsushita, T., and Magara, Y. (2010).

392 Exposure assessment of metal intakes from drinking water relative to those from total diet in

393 Japan. Water science and technology : a journal of the International Association on Water

394 Pollution Research 62, 2694-2701. https://doi.org/10.2166/wst.2010.392

395 Özel, Ş., Ozyer, S., Aykut, O., Çinar, M., Yılmaz, O.H., Caglar, A., and Engin-Ustun, Y.

396 (2019). Maternal second trimester blood levels of selected heavy metals in pregnancies

397 complicated with neural tube defects. J Matern Fetal Neonatal Med 32, 2547-2553.

398 https://doi.org/10.1080/14767058.2018.1441280

399 Radhika, G., Sathya, R., Sudha, V., Ganesan, A., and Mohan, V. (2007). Dietary salt intake 400 and hypertension in an urban south Indian population-[CURES-53]. Journal of Association of 401 Physicians of India 55, 405-411.

402 Sarath, T.S., Waghe, P., Gupta, P., Choudhury, S., Kannan, K., Pillai, A.H., Harikumar, S.K., 403 Mishra, S.K., and Sarkar, S.N. (2014). Atorvastatin ameliorates arsenic-induced hypertension 404 and enhancement of vascular redox signaling in rats. Toxicology and applied pharmacology 280, 443-454. https://doi.org/10.1016/j.taap.2014.08.032

406 Shah, A.Q., Kazi, T.G., Arain, M.B., Jamali, M.K., Afridi, H.I., Jalbani, N., Baig, J.A., and

407 Kandhro, G.A. (2009). Accumulation of arsenic in different fresh water fish species-potential 408 contribution to high arsenic intakes. Food Chemistry 112, 520-524.

409 https://doi.org/10.1016/j.foodchem.2008.05.095

410 Stone, M.S., Martyn, L., and Weaver, C.M. (2016). Potassium Intake, Bioavailability,

411 Hypertension, and Glucose Control. Nutrients 8. https://doi.org/10.3390/nu8070444

412 Strazzullo, P., Barba, G., Cappuccio, F.P., Siani, A., Trevisan, M., Farinaro, E., Pagano, E., 413 Barbato, A., Iacone, R., and Galletti, F. (2001). Altered renal sodium handling in men with 414 abdominal adiposity: a link to hypertension. Journal of hypertension 19, 2157-2164. doi:

$415 \quad 10.1097 / 00004872-200112000-00007$

416 Uneyama, C., Toda, M., Yamamoto, M., and Morikawa, K. (2007). Arsenic in various foods: 417 cumulative data. Food Addit Contam 24, 447-534.

418 https://doi.org/10.1080/02652030601053121

419 Wu, W., Jiang, S., Zhao, Q., Zhang, K., Wei, X., Zhou, T., Liu, D., Zhou, H., Zeng, Q., 420 Cheng, L., et al. (2018). Environmental exposure to metals and the risk of hypertension: A 
421 cross-sectional study in China. Environmental pollution (Barking, Essex : 1987) 233, 670-

422 678. https://doi.org/10.1016/j.envpol.2017.10.111

423 Yajima, I., Ahsan, N., Akhand, A.A., Al Hossain, M.A., Yoshinaga, M., Ohgami, N., Iida, 424 M., Oshino, R., Naito, M., Wakai, K., et al. (2018). Arsenic levels in cutaneous appendicular 425 organs are correlated with digitally evaluated hyperpigmented skin of the forehead but not the 426 sole in Bangladesh residents. Journal of exposure science \& environmental epidemiology 28, 427 64-68. https://doi.org/10.1038/jes.2016.70

428 Yajima, I., Kumasaka, M.Y., Iida, M., Oshino, R., Tanihata, H., Al Hossain, A., Ohgami, N., 429 and Kato, M. (2017). Arsenic-mediated hyperpigmentation in skin via NF-kappa

430 B/endothelin-1 signaling in an originally developed hairless mouse model. Archives of 431 toxicology 91, 3507-3516. https://doi.org/10.1007/s00204-017-1975-0

432 Yajima, I., Kumasaka, M.Y., Ohnuma, S., Ohgami, N., Naito, H., Shekhar, H.U., Omata, Y., 433 and Kato, M. (2015). Arsenite-mediated promotion of anchorage-independent growth of 434 HaCaT cells through placental growth factor. The Journal of investigative dermatology 135, 435 1147-1156. https://doi.org/10.1038/jid.2014.514

436 Zhong, Q., Zhang, C., Zhang, Q., Jiang, C.X., Qin, Q.R., Chen, J., Liang, L., and Huang, F. 437 (2019). Arsenic Exposure and Incident Hypertension of Adult Residents Living in Rural 438 Areas Along the Yangtze River, Anhui, China. Journal of occupational and environmental 439 medicine / American College of Occupational and Environmental Medicine 61, 271-277. doi: 440 10.1097/JOM.0000000000001511 
Table 1. Basic characteristics of the subjects

\begin{tabular}{ll}
\hline Variables & Values \\
\hline Number of subjects $\dagger$ & $2709(100)$ \\
Arsenic levels in fasting serum $(\mu \mathrm{g} / \mathrm{L}) \dagger$ & $0.7(0-2.2)$ \\
Age $($ years $) *$ & $58.9 \pm 9.8$ \\
Male $(\%) \dagger$ & $724(26.7)$ \\
Body mass index $\left(\mathrm{kg} / \mathrm{m}^{2}\right) *$ & $21.6 \pm 3.2$ \\
Physical activity $(\mathrm{METs} / \mathrm{W}) \dagger$ & $8.7(0.9-18.3)$ \\
Current smoker $(\%) \dagger$ & $193(7.2)$ \\
Current drinker $(\%) \dagger$ & $1383(51.1)$ \\
Family history of hypertension $(\%) \dagger$ & $1324(48.9)$ \\
Hypertension $\dagger$ & $697(25.7)$ \\
Food intake frequency (times/daily) $\dagger$ & \\
Cereal/beans & $4.1(3.4-4.8)$ \\
Livestock/dairy products & $4.2(3.1-5.3)$ \\
Seafood & $1.3(0.8-1.8)$ \\
Vegetables/fruits & $4.5(3.0-6.3)$ \\
Confectionery & $0.1(0.1-0.4)$ \\
Beverages & $7.0(4.7-8.9)$ \\
\hline$\dagger$ Number $($ Percentage $)$ & \\
+ Median $(25$ th -75 th $)$ & \\
$*$ Means \pm SD. &
\end{tabular}


Table 2. Pseudo R Square (\%) in logistic regression model

Variables

Serum arsenic levels

Food category

\begin{tabular}{lll} 
& Seafood & $\mathbf{2 5 . 2 5}$ \\
Livestock/dairy & 9.63 \\
Vegetables/fruits & 4.94 \\
Cereals/bean & 1.82 \\
Beverage & 1.82 \\
Confectionery & 0.25 \\
Confounders & & \\
& Age & 33.07 \\
Drinking & 0.12 \\
Smoking & 0.07 \\
BMI & 1.82 \\
Gender & 0.60 \\
Redundancy & 20.61 \\
\hline
\end{tabular}

444 


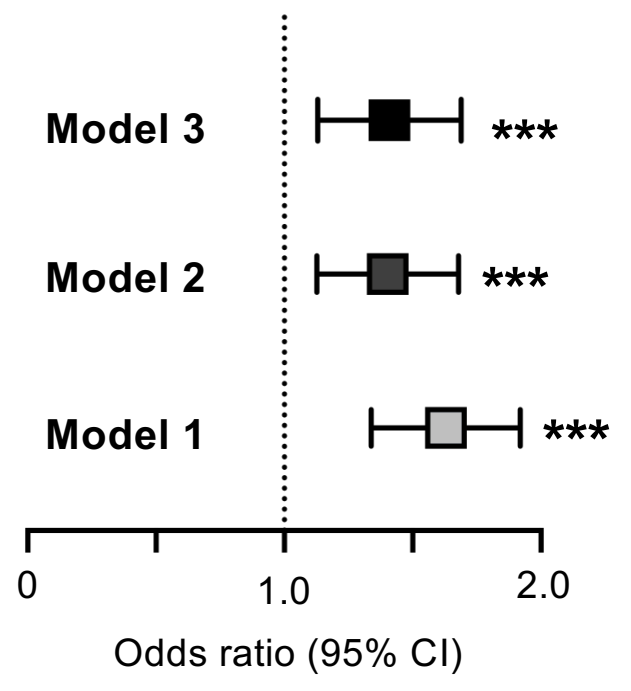

Figure. 1. Associations between serum levels of arsenic and hypertension. Associations between fasting serum level of arsenic and prevalence of hypertension analyzed by logistic regression are shown. Model $\mathbf{1}$ is a model without any adjustments, model $\mathbf{2}$ was adjusted with age, BMI, smoking, drinking, family history of hypertension and physical activity during leisure time, and model $\mathbf{3}$ was adjusted with fasting serum levels of sodium and potassium in addition to the covariates in model $2 .{ }^{* *} P<0.001$. 


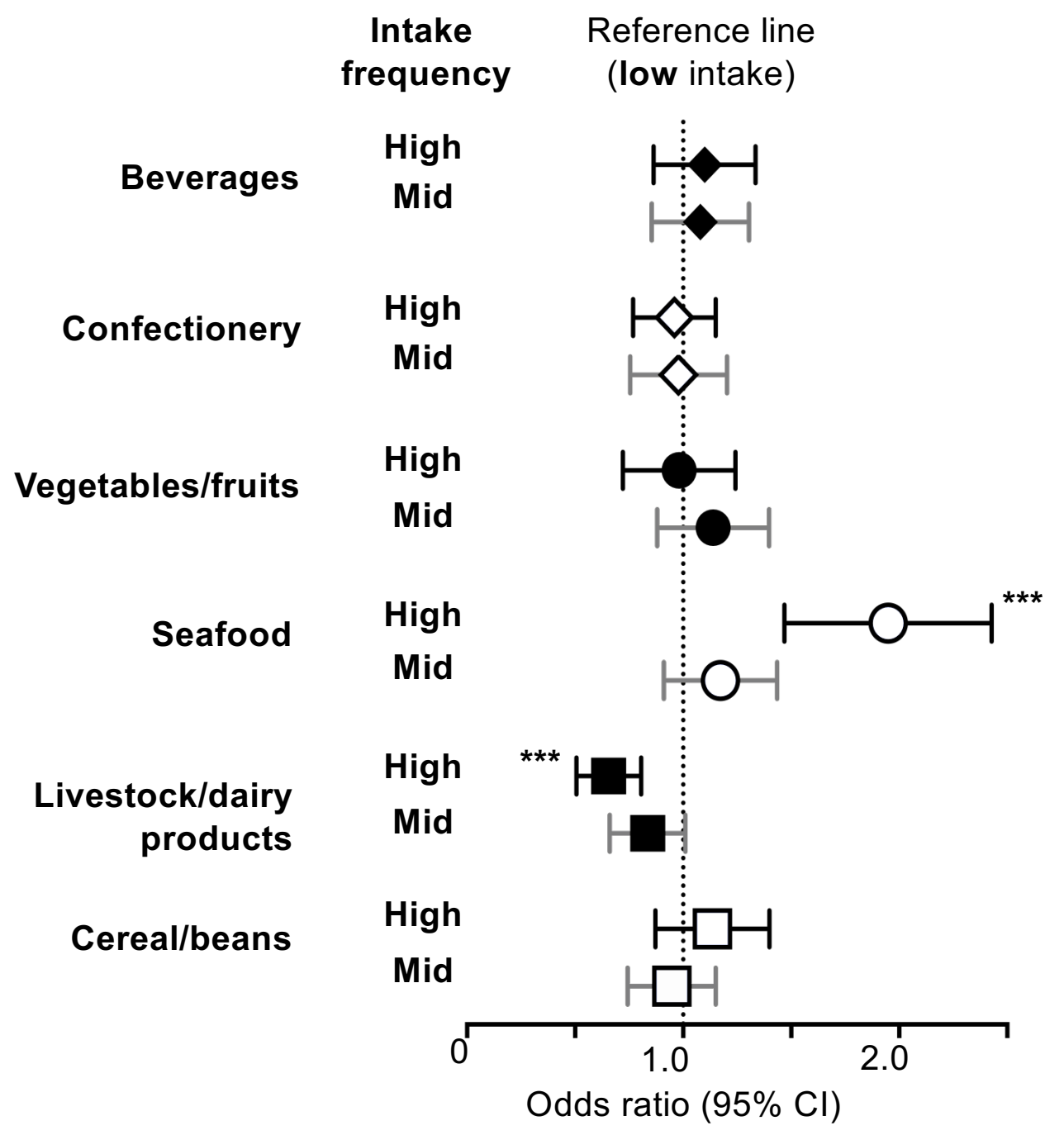

Figure. 2. Associations between frequencies of food intake and serum level of arsenic. Associations between frequencies of intake of cereal/beans, livestock/dairy products, seafood, vegetables/fruits, confectionery and beverages and fasting serum levels of arsenic analyzed by logistic regression are shown. Models were adjusted with age, gender, BMI, smoking and drinking besides food intake. Mid, medium intake; High, high intake; ${ }^{* *} P<0.01$; ${ }^{* *} P<0.001$. 


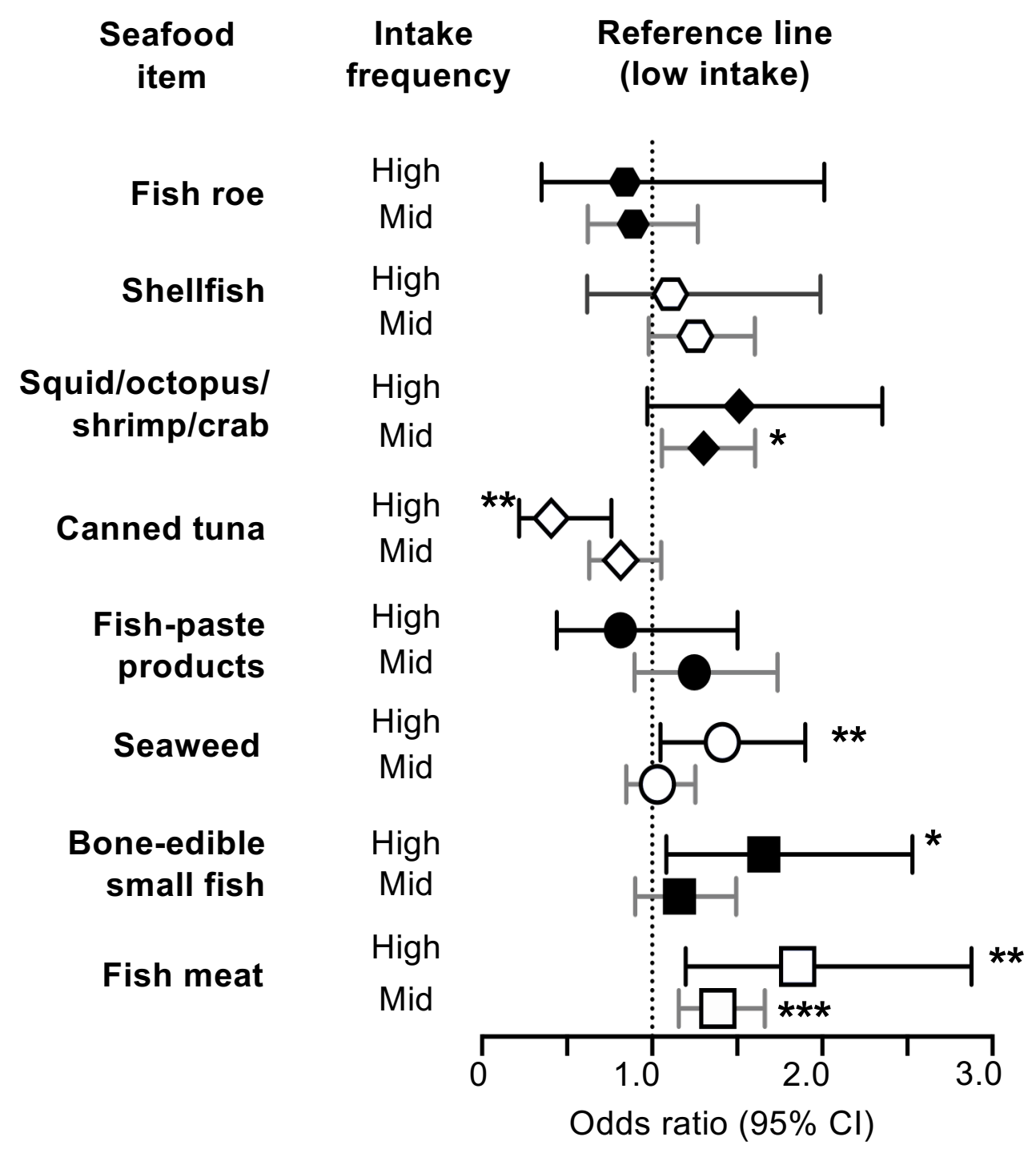

Figure. 3. Associations between frequencies of intake of seafood items and serum levels of arsenic. Associations between frequencies of intake of 8 kinds of seafood items and fasting serum levels of arsenic analyzed by logistic regression are shown. Models were adjusted with age, gender, BMI, smoking and drinking besides seafood intake. Mid, medium intake; High, high intake; ${ }^{*} P<0.05 ;{ }^{* *} P<0.01 ;{ }^{* * *} P<0.001$. 


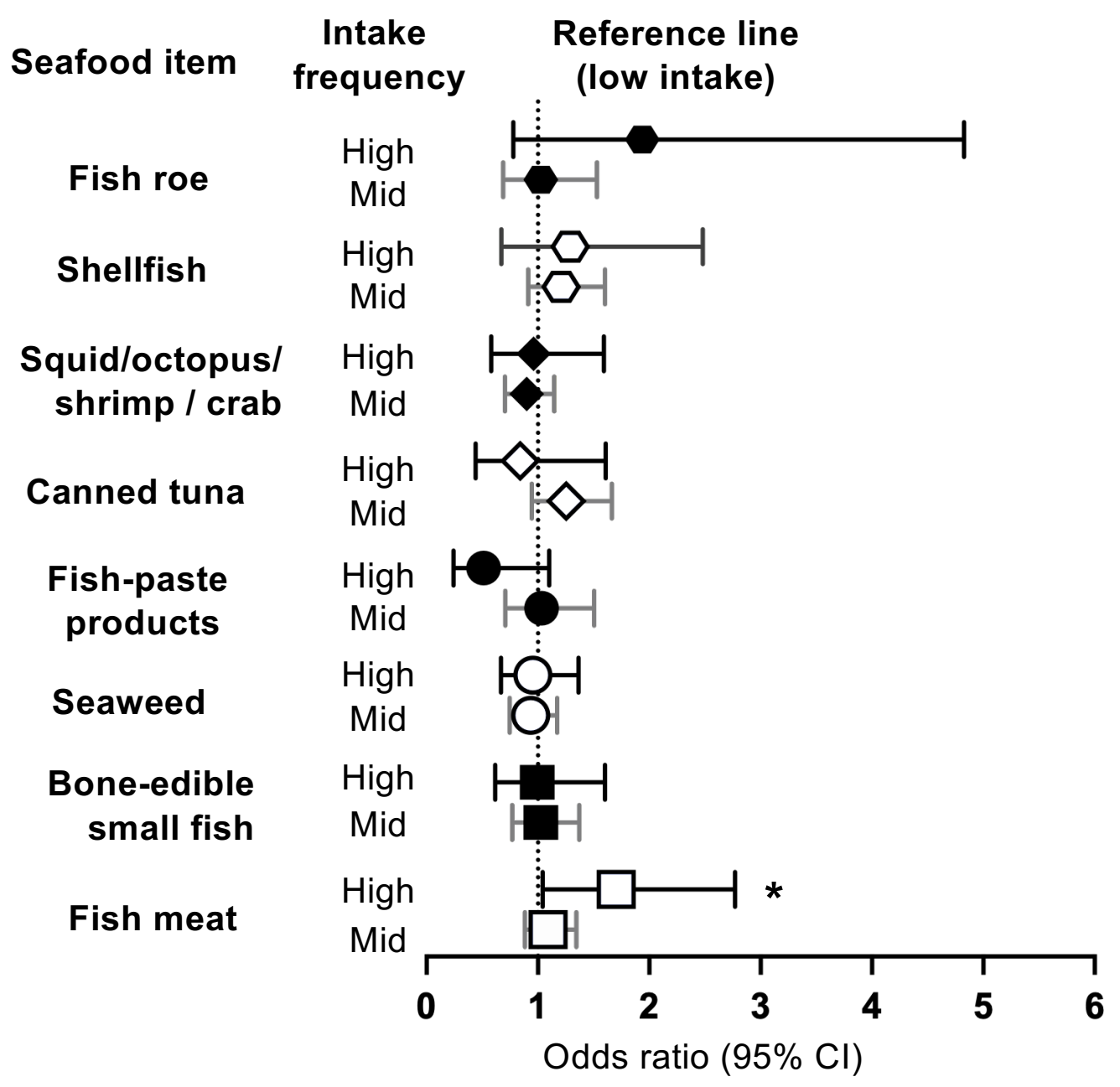

Figure. 4. Associations between frequencies of intake seafood items and hypertension. Associations between frequencies of intake of 8 kinds of seafood items and prevalence of hypertension analyzed by logistic regression are shown. Models were adjusted with age, gender, BMI, smoking, drinking, family history of hypertension, physical activity, and ratios of sodium and potassium in fasting serum besides intake of seafood items. Mid, medium intake; High, high intake; ${ }^{*} P<0.05$; ${ }^{* *} P<0.01 ;{ }^{* *} P<0.001$. 